$04.1 ; 13.4$

\title{
Особенности инициирования эффекта полого катода в электродной системе тлеющего разряда с протяженной катодной щелью
}

\author{
() А.С. Климов ${ }^{1}$, И.Ю. Бакеев ${ }^{1}$, А.А. Зенин ${ }^{1}$, Е.М. Окс ${ }^{1,2}$, В.Т. Чан ${ }^{1}$ \\ ${ }^{1}$ Томский государственный университет систем управления и радиоэлектроники, Томск, Россия \\ ${ }^{2}$ Институт сильноточной электроники СО РАН, Томск, Россия \\ E-mail: klimov@main.tusur.ru
}

Поступило в Редакцию 20 мая 2021 г.

В окончательной редакции 3 июля 2021 г.

Принято к публикации 6 июля 2021 г.

\begin{abstract}
Представлены результаты исследований влияния размеров катодной щели на инициирование эффекта полого катода в системе тлеющего разряда с протяженным прямоугольным полым катодом. Установлено, что пороговый ток перехода разряда в режим горения с полым катодом определяется размерами катодной щели. С уменьшением ширины щели пороговый ток непропорционально возрастает, с увеличением продольного размера щели этот ток резко снижается.
\end{abstract}

Ключевые слова: тлеющий разряд, катодный слой, протяженный полый катод, эффект полого катода.

DOI: 10.21883/PJTF.2021.20.51609.18880

Тлеющий разряд с полым катодом привлекает внимание исследователей и разработчиков на протяжении достаточно длительного периода времени [1]. В разрядах такого типа в результате электростатического удержания электронов в катодной полости и их многократной осцилляции обеспечиваются эффективная ионизация рабочего газа и генерация плазмы [2]. Именно поэтому разряд с полым катодом находит широкое применение в различных электроразрядных устройствах, включая ионные источники [3] и плазменные источники электронных пучков различной конфигурации [4,5].

Для электронных пучков ленточной конфигурации в разрядной системе электронного источника используется протяженный прямоугольный полый катод с продольной щелью в одной из стенок, обращенной к аноду [6]. Источники электронов такого типа также позволяют формировать ленточные электронные пучки в условиях форвакуумного диапазона давлений, где они используются для генерации плотной пучковой плазмы $[7,8]$. Для протяженного прямоугольного полого катода пороговый ток инициирования эффекта полого катода, по-видимому, может определяться как шириной катодной щели, так и ее длиной. Изучение влияния размеров катодной щели на процессы зажигания разряда в катодной полости и являлось целью исследований, результаты которых представлены в настоящей работе.

Для проведения экспериментов использовалась разрядная система форвакуумного плазменного источника ленточного электронного пучка (рис. 1). Разрядная система состояла из выполненных из нержавеющей стали протяженного полого катода 1 прямоугольного сечения и плоского анода 2. Внутренние размеры катодной полости составляли $120 \times 30 \times 70 \mathrm{~mm}$. В полости вдоль ее длинной стороны имелась протяженная щель 3 , длину $l$ и ширину $d$ которой можно было изменять в результа- те установки соответствующих вкладышей в пределах от 0.4 до $100 \mathrm{~mm}$ и от 0.4 до $2 \mathrm{~mm}$ соответственно. Анод представлял собой плоскость, удаленную от нижней торцовой плоскости полого катода на $5 \mathrm{~mm}$. В аноде было выполнено прямоугольное эмиссионное окно 4 размером $120 \times 10 \mathrm{~mm}$. Эмиссионное окно было перекрыто мелкоструктурной вольфрамовой сеткой с размерами ячейки $0.6 \times 0.6 \mathrm{~mm}$ и геометрической прозрачностью $60 \%$. Наличие сеточного окна позволяло наблюдать свечение разрядной плазмы и визуально оценивать ее однородность. Размещение за сеткой перемещаемого малого ионного коллектора 5 в виде диска диаметром $3 \mathrm{~mm}$ позволяло определить профиль распределения плотности плазмы вдоль протяженной оси катодной щели. Напряжение от 0.1 до $10 \mathrm{kV}$ на разрядный промежуток подавалось от стабилизированного источника питания 6 (Spellman SR6) через балластное сопротивление $10 \mathrm{k} \Omega$. Максимальное значение тока разряда составляло $300 \mathrm{~mA}$ и ограничивалось источником питания

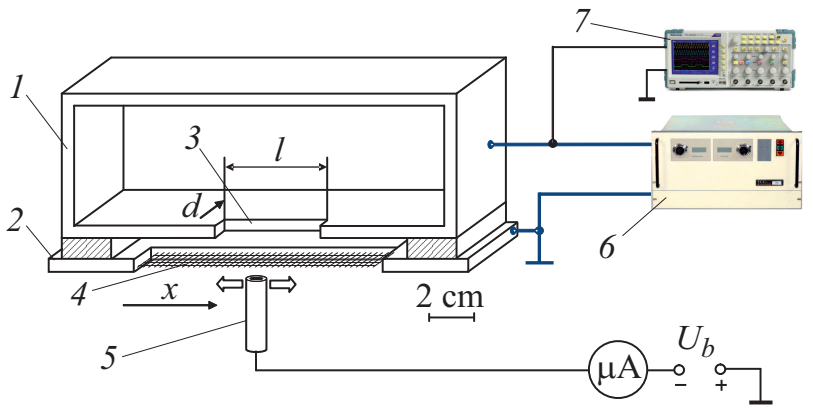

Рис. 1. Схема разрядной системы электронного источника. 1 - протяженный полый катод прямоугольной формы, 2 - плоский анод, 3 - щелевидная апертура в катоде, 4 - эмиссионное сеточное окно, 5 - малый коллектор ионов, 6 - высоковольтный источник питания, 7 - осциллограф. 


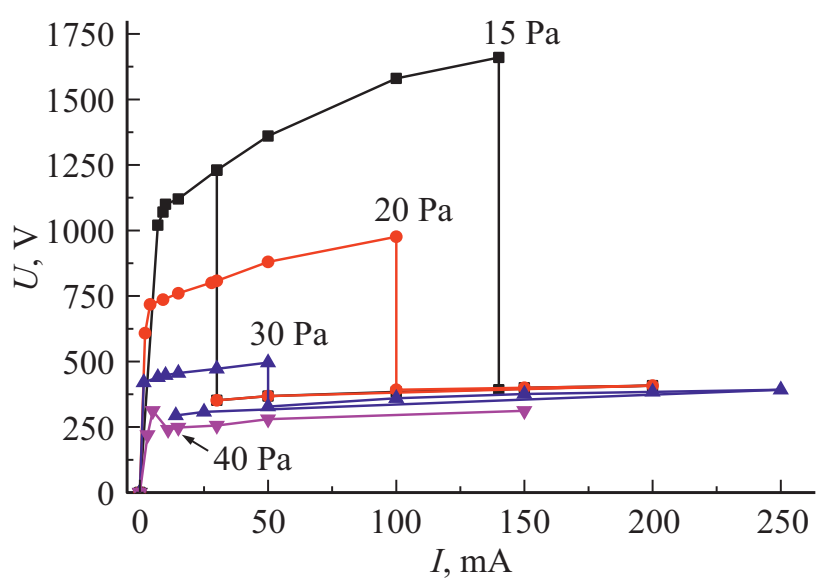

Рис. 2. ВАХ разряда в зависимости от давления внутри камеры при ширине щели $1 \mathrm{~mm}$ и длине $18 \mathrm{~mm}$.

разряда. Измерение падения напряжения на разрядном промежутке осуществлялось высоковольтным щупом TESTEC HVP-15HR, подключенным к осциллографу 7 Tektronix2024B.

Вакуумная камера откачивалась механическим насосом до предельного давления 2-3 Ра. Давление газа (аргона) в камере регулировалось игольчатым натекателем в диапазоне от 15 до $50 \mathrm{~Pa}$. За напряжение зажигания разряда принималось напряжение, предшествующее появлению сколь-нибудь заметного тока в цепи катода. Для точного определения порогового тока инициирования эффекта полого катода ток разряда сразу после его зажигания ограничивался на уровне $10 \mathrm{~mA}$. Далее ток разряда повышался, и при определенной его величине наблюдалось резкое снижение напряжения горения разряда, что соответствовало проникновению плазмы в катодную полость и инициированию эффекта полого катода.

Как и следовало ожидать, на пороговый ток зажигания разряда в катодной полости наряду с давлением газа оказывают влияние ширина и длина катодной щели, однако степень влияния заметно различается. Для длины щели $100 \mathrm{~mm}$ даже при ее минимально возможной ширине $0.4 \mathrm{~mm}$ разряд проникает в катодную полость уже при пороговом токе в единицы $\mathrm{mA}$. При меньших длинах щели в зависимости от тока разряд может либо только гореть между плоскими частями катода и анода, либо при большем токе замыкаться также на внутреннюю поверхность катодной полости (рис. 1). На рис. 2 представлены вольт-амперные характеристики $(\mathrm{BAX})$ разряда для различных давлений газа при протяженности щели в катоде $l=18 \mathrm{~mm}$ (ширина щели $d=1 \mathrm{~mm})$.

Вид BAX на рис. 2 соответствует типичной ВАХ разряда с полым катодом. При определенном пороговом токе разряда $I_{m}$ происходит резкое снижение напряжения горения разряда, соответствующее переходу разряда в режим горения с полым катодом. Из представленных на рис. 2 данных также видно, что пороговый ток $I_{m}$ ожидаемо снижается с повышением давления рабочего газа.

Зависимость порогового тока перехода разряда в режим горения с полым катодом от длины щели $l$ представлена на рис. 3, $a$. Следует отметить, что при ширине щели в полости $0.4 \mathrm{~mm}$ минимальная ее протяженность, при которой наблюдалось возникновение эффекта полого катода, составляла величину $l=24 \mathrm{~mm}$. Для щели с $d=1 \mathrm{~mm} l=18 \mathrm{~mm}$, а для щели шириной $2 \mathrm{~mm}$ для проникновения плазмы в полость было достаточно длины щели $2 \mathrm{~mm}$. Щель в катоде с размерами $2 \times 2 \mathrm{~mm}$ по сути являлась моделью одиночного отверстия в полом катоде. Тем не менее сравнение условий инициирования эффекта полого катода в случае круглого отверстия показало, что при диаметре отверстия $2 \mathrm{~mm}$ проникновение разряда в катодную полость происходит при несколько бо́льших значениях тока разряда.

Проникновение разряда в полость и инициирование эффекта полого катода происходит, как известно, в результате „разрыва“ ионного слоя, отделяющего плазму от стенок катода. Очевидно, что протяженность ионного слоя в случае узкой щели довольно высока по сравнению с поперечными размерами щели в катодной полости, и разряд не может проникнуть в полый катод. Для простой оценки протяженности катодного слоя можно пренебречь электронами в слое и считать его исключительно ионным. Тогда решение уравнения Пуассона сводится к закону „степени $3 / 2^{“}$ для ионов

$$
j_{i}=\frac{4}{9} \sqrt{\frac{2 e}{M_{i}}} \frac{\varepsilon_{0} U_{c}^{3 / 2}}{l_{c}^{2}},
$$

где $U_{c}$ - разность потенциалов на слое или разность потенциалов между плазмой и катодом $[\mathrm{V}], l_{c}$ - протяженность слоя $[\mathrm{m}], e-$ заряд электрона $[\mathrm{C}], M_{i}$ - масса иона газа (для азота $M_{i}=66.8 \cdot 10^{-27} \mathrm{~kg}$ ). Сравнивая с формулой Бома для плотности ионного тока из плазмы, получаем

$$
j_{i} \approx 0.4 e n_{0} \sqrt{\frac{k T_{e}}{M_{i}}},
$$

где $n_{0}-$ концентрация плазмы $\left[\mathrm{m}^{-3}\right], k-$ постоянная Больцмана $\left(1.38 \cdot 10^{-23} \mathrm{~J} / \mathrm{K}\right)$.

Для протяженности слоя получаем выражение

$$
l_{c} \approx 0.2 \frac{1}{\sqrt{j_{i}}} \sqrt{\frac{\varepsilon_{0} \sqrt{e} U_{c}^{3 / 2}}{\sqrt{M_{i}}}} .
$$

Плазма, как известно, проникает в катодную полость при равенстве толщины слоя половине поперечного размера отверстия в катоде:

$$
l_{c} \leqslant \frac{d}{2}
$$

где $d-$ ширина узкой части катодной полости либо диаметр отверстия $[\mathrm{m}]$. 

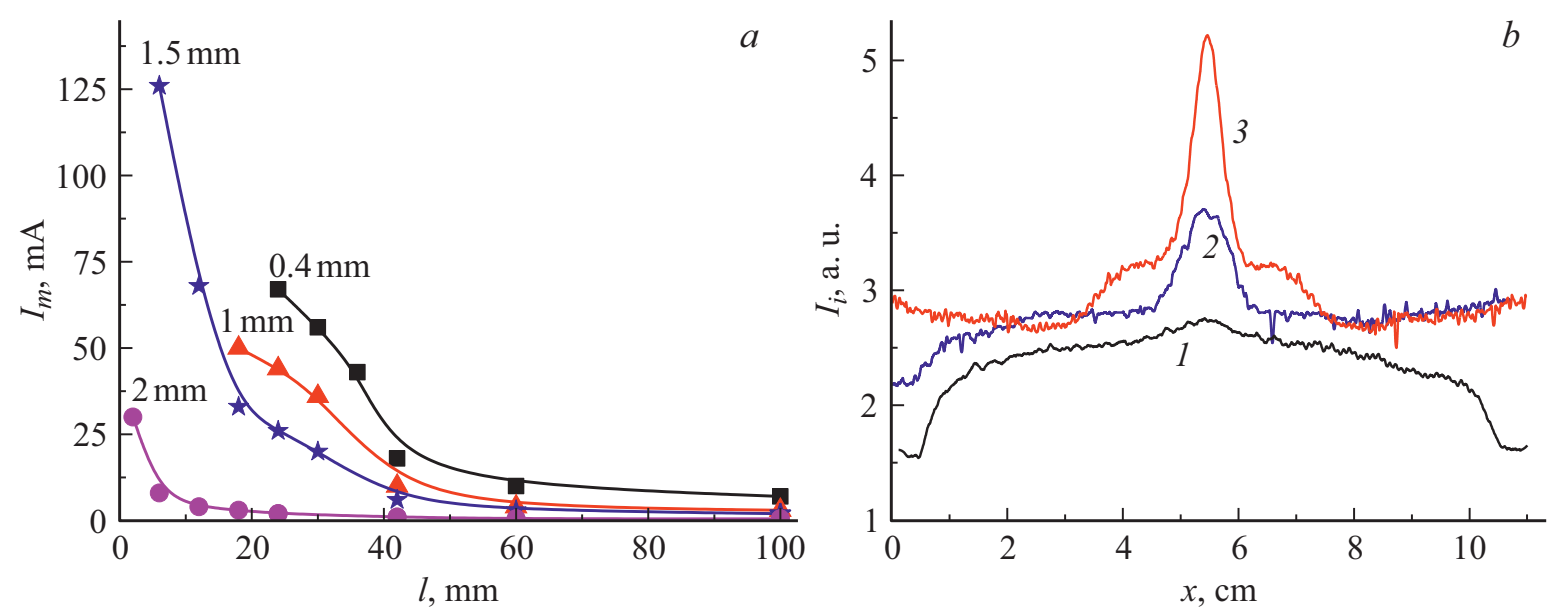

Рис. 3. $a-$ зависимость порогового тока перехода от длины щели при различной ширине щели, давление 30 Ра. $b-$ распределение ионного тока из плазмы: 1 - щель отсутствует, 2 - щель $1 \times 18 \mathrm{~mm}, 3$ - щель $1 \times 36 \mathrm{~mm}$; давление 30 Ра (аргон), ток разряда $10 \mathrm{~mA}$.

Катодное падение потенциала, как правило, слабо зависит от величины тока разряда, и основным фактором, влияющим на протяженность катодного слоя, оказывается концентрация плазмы либо, как следует из (3), плотность разрядного тока $j_{i}$. Из выражения (3) следует, что с ростом $j_{i}$ снижается протяженность катодного слоя, и при выполнении условия (4) плазма проникает в полость. Подставляя в (3) измеренные в эксперименте значения параметров разряда (см. рис. 2 и $3, a)$ и оценивая для простоты плотность тока разряда как отношение тока разряда к площади открытой части катода за вычетом площади щели, получаем, что при $U_{c}=1600 \mathrm{~V}, I_{d}=140 \mathrm{~mA}, M_{i}=66.8 \cdot 10^{-27} \mathrm{~kg}$ протяженность слоя составляет $1.2 \mathrm{~mm}$, что сравнимо с поперечным размером щели в $1 \mathrm{~mm}$. Здесь за падение напряжения на катодном слое было принято напряжение разряда, поскольку потенциал плазмы в представленных условиях, как правило, близок к потенциалу анода. С ростом давления и снижением $U_{c}$ с 1600 до $400 \mathrm{~V}$ (рис. 2) протяженность слоя уменьшается, что и приводит к проникновению плазмы в катодную полость при меньших токах разряда.

Расчет по формуле (3) дает для ширины щели в катоде $d=0.4 \mathrm{~mm}$, т.е. для $l_{c}<0.2 \mathrm{~mm}$, требуемую величину тока разряда порядка $6 \mathrm{~A}$, однако, как следует из рис. $3, a$, экспериментальные значения более чем на порядок меньше и в данном случае ток разряда составляет $75 \mathrm{~mA}$. Протяженность ионного слоя при токе разряда $75 \mathrm{~mA}$ и давлении $30 \mathrm{~Pa}$ составляет $0.75 \mathrm{~mm}$. Эта величина почти в 4 раза больше, чем $d / 2$, и условие (4) для ширины не выполняется. Однако если применить условие проникновения плазмы в катодную полость для протяженности щели в катоде $l$, то получается, что условие (4) может быть выполнено, поскольку при протяженности щели $2 \mathrm{~mm} l_{c}<l / 2$. Однако, как следует из результатов экспериментов, плазма проникает в катодную полость при другом соотношении между $l$ и $l_{c}$.
Можно предположить, что на проникновение разряда в катодную полость оказывают влияние не сами размеры катодной щели, а их соотношение. Но, как следует из эксперимента, уменьшение ширины щели в 2.5 раза (с 1 до $0.4 \mathrm{~mm}$ ) приводило к возрастанию тока перехода в 2 раза (с 56 до $114 \mathrm{~mA}$ ) при давлении 20 Ра и в 3.5 раза (c 9 до $32 \mathrm{~mA}$ ) при давлении $40 \mathrm{~Pa}$. При уменьшении ширины щели с 2 до $1 \mathrm{~mm}$ ток возрастает уже более чем в 10 раз (с 4 до $56 \mathrm{~mA}$ ). Следует отметить, что чем меньше ширина щели, тем большие значения имеют ее протяженность и давление газа. Для ширины щели в $2 \mathrm{~mm}$ переход разряда в полость имеет место при токах, не превышающих несколько $\mathrm{mA}$, т. е. практически сразу при зажигании разряда между плоскими частями катода и анода. В то же время для более узкой щели требуются токи в сотни $\mathrm{mA}$.

Измерения тока ионов из плазмы на малый коллектор, расположенный за анодной сеткой и перемещающийся вдоль продольной оси разрядной системы, показали следующее. В отсутствие щели разряд, очевидно, реализуется только в области между торцевой частью полого катода и плоским анодом. В этом случае профиль распределения ионного тока, отражающий в определенной степени распределение плотности плазмы, довольно однородный (кривая 1 на рис. $3, b$ ). При токах разряда ниже пороговых разряд также горит только в области между плоскими электродами. Наличие щели приводит к появлению неоднородности распределения плотности плазмы вдоль протяженного размера полости с выраженным максимумом в центральной части разрядного промежутка (кривые 2 и 3 на рис. $3, b$ ). Степень неоднородности плотности плазмы заметно повышается с увеличением протяженности катодной щели. Возникающая неоднородность плотности плазмы приводит к уменьшению протяженности катодного слоя в локальной области катодной щели и тем самым стимулирует 
разрыв в этом месте ионного слоя и инициирование эффекта полого катода.

Таким образом, для тлеющего разряда с протяженным прямоугольным полым катодом и протяженной катодной щелью на пороговый ток инициирования эффекта полого катода оказывают влияние размеры катодной щели. Даже в случае узкой катодной щели, для которой условие разрыва катодного слоя заведомо не выполняется, увеличение длины щели приводит к проникновению плазмы в катодную полость. Такое влияние протяженности катодной щели может быть связано с усилением неоднородности распределения плотности разрядной плазмы при токах разряда ниже пороговых для инициирования эффекта полого катода. Результаты проведенных исследований позволяют более обоснованно подходить к выбору геометрии протяженной прямоугольной полости и катодной щели при создании различных электроразрывных устройств на основе тлеющего разряда с протяженным полым катодом.

\section{Финансирование работы}

Работа выполнена при поддержке Министерства высшего образования и науки (грант FEWM-2020-0038).

\section{Конфликт интересов}

Авторы заявляют, что у них нет конфликта интересов.

\section{Список литературы}

[1] Б.И. Москалев, Разряд с полым катодом (Энергия, М., 1969).

[2] А.С. Метель, С.Н. Григорьев, Тлеющий разряд с электростатическим удержсанием электронов. Физика, техника, применение (МГТУ „Станкин“, М., 2005).

[3] N.V. Gavrilov, G.A. Mesyats, G.V. Radkovski, V.V. Bersenev, Surface Coat. Technol., 96 (1), 81 (1997).

[4] В.А. Бурдовицин, Е.М. Окс, Изв. вузов. Физика, 63 (10), 33 (2020). DOI: 10.17223/00213411/63/10/33 [V.A. Burdovitsin, E.M. Oks, Russ. Phys. J., 63, 1678 (2021). DOI: $10.1007 / \mathrm{s} 11182-021-02221-9]$.

[5] А.П. Семенов, ЖТФ, 77 (2), 131 (2007). [A.P. Semenov, Tech. Phys., 52 (2), 276 (2007). DOI: 10.1134/S1063784207020211].

[6] W.M. Manheimer, R.F. Fernsler, M. Lampe, R.A. Meger, Plasma Sources Sci. Technol., 9 (3), 37 (2000).

DOI: $10.1088 / 0963-0252 / 9 / 3 / 316$

[7] I.Y. Bakeev, A.S. Klimov, E.M. Oks, A.A. Zenin, Plasma Sources Sci. Technol., 27 (7), 075002 (2018).

DOI: 10.1088/1361-6595/aacb55

[8] А.С. Климов, М.И. Ломаев, Е.М. Окс, А.П. Андрейчик, ЖТФ, $87 \quad$ (2), $192 \quad$ (2017). DOI: 10.21883/JTF.2017.02.44124.1825 [A.S. Klimov, M.I. Lomaev, E.M. Oks, A.P. Andreichik, Tech. Phys., 62 (2), 218 (2017). DOI: 10.1134/S1063784217020128]. 